This item was submitted to Loughborough's Research Repository by the author.

Items in Figshare are protected by copyright, with all rights reserved, unless otherwise indicated.

\title{
The ALSTOM benchmark challenge on gasifier control
}

\section{PLEASE CITE THE PUBLISHED VERSION}

https://doi.org/10.1243/0959651001540744

\section{PUBLISHER}

SAGE @ IMechE

\section{VERSION}

AM (Accepted Manuscript)

\section{PUBLISHER STATEMENT}

This work is made available according to the conditions of the Creative Commons Attribution-NonCommercialNoDerivatives 4.0 International (CC BY-NC-ND 4.0) licence. Full details of this licence are available at: https://creativecommons.org/licenses/by-nc-nd/4.0/

\section{LICENCE}

CC BY-NC-ND 4.0

\section{REPOSITORY RECORD}

Dixon, Roger, A.W. Pike, and M.S. Donne. 2019. "The ALSTOM Benchmark Challenge on Gasifier Control". figshare. https://hdl.handle.net/2134/26962. 


\title{
The ALSTOM Benchmark Challenge On Gasifier Control
}

\author{
R. Dixon, A.W. Pike, M.S. Donne
}

ALSTOM Power Technology Centre, Cambridge Rd, Whetstone, Leicester, LE8 6LH, UK

Email: roger.dixon@power.alstom.com

\begin{abstract}
Integrated Gasification Combined Cycle (IGCC) power plants are being developed around the world to provide environmentally clean and efficient power generation from coal. As part of the UK's Clean Coal Power Generation Group, ALSTOM ${ }^{1}$ has undertaken a detailed feasibility study on the development of a small scale Prototype Integrated Plant (PIP), based on the Air Blown Gasification Cycle (ABGC). In pursuit of this goal the ALSTOM Power Technology Centre ${ }^{2}$ has produced a comprehensive dynamic model and control philosophy for the PIP, $[1,2]$. The gasifier is one component of the model which, being a highly coupled multivariable system with five inputs (coal, limestone, air, steam and char extraction) and four outputs (pressure, temperature, bed mass and gas quality), has been found to be particularly difficult to control. For this reason the gasifier together with its associated control specification, operating constraints and various disturbance characteristics, has been selected as the subject for this control challenge. This paper provides a brief background to the problem and describes the control specification and closed-loop tests to be performed.
\end{abstract}

\footnotetext{
${ }^{1}$ formerly GEC ALSTHOM

${ }^{2}$ formerly GEC ALSTHOM Mechanical Engineering Centre
} 


\section{NOTATION}

CVGAS fuel gas calorific value

MASS gasifier bed mass

PGAS fuel gas pressure

PSINK sink pressure (to gas turbine fuel inlet)

TGAS fuel gas temperature

WCOL $\quad$ coal inlet mass flow

WCHR char extraction mass flow

WLS limestone inlet mass flow

WSTM steam inlet mass flow

\section{INTRODUCTION}

There were two primary reasons for issuing the Benchmark Challenge:

1) Gasifier control is a real industrial problem facing the providers of power generating plant and poses a major challenge even for today's advanced control techniques. By collaborating on such a problem, both industry and academia should benefit from a better understanding not only of the problem but also of the application of the various techniques.

2) The challenge itself (irrespective of the application) provides a rare platform for participants to present and compare a number of control system design approaches on an industrial plant model, with a formal set of design criteria and specifications. 
The purpose of this paper is to provide an introduction to and specification for the Benchmark Challenge. In Section 2, a brief summary is given of the Air Blown Gasification Cycle (ABGC), as proposed by the UK's Clean Coal Power Generation Group (CCPGG). The paper then gives a short introduction to the gasifier itself, describing some of the fundamental processes occurring in a gasifier and giving an overview of The Technology Centre's non-linear gasifier model. Section 3, outlines the control problem - including a description of the plant inputs and outputs, the three linear plant models and the control system specification for the gasifier (as defined for the purposes of the challenge); finally, a number of test conditions are described under which the closed-loop system is to be evaluated.

\section{BACKGROUND}

As a result of recommendations contained in a Government White Paper [3] regarding future markets for coal, an industry-led consortium was set up to continue the development of a coalbased advanced power generation system. Known as the CCPGG, the consortium was lead by GEC ALSTHOM, Stein Industrie SA and EVT GmbH. The other members were Mitsui Babcock Energy Ltd, PowerGen plc and the Coal Technology Development Division (CTDD) of the British Coal Corporation.

Around the world, IGCC power plants combining gasification with a gas and steam cycle are being developed to provide environmentally clean and efficient power generation from coal, [4]. Plants which are currently operational include Buggenum (the Netherlands) and Wabash River (USA). A number of others are in construction, including Tampa, Toms Creek, Pinon Pine (USA) and Puertollano (Spain). Additional background information on the current state of the technology may be found in [4].

The programme undertaken by CCPGG addressed development of the key components of an 87 MW Prototype Integrated Plant (PIP) based upon the ABGC shown in Figure 1. This 
programme also involved undertaking technical and economic assessments for a fully integrated commercial-scale plant.

Following the successful completion of the CCPGG's programme, a new consortium was formed to further progress the development of the ABGC. This consortium has recently completed an EC THERMIE supported programme to perform pre-engineering studies for an 85 MW demonstration plant.

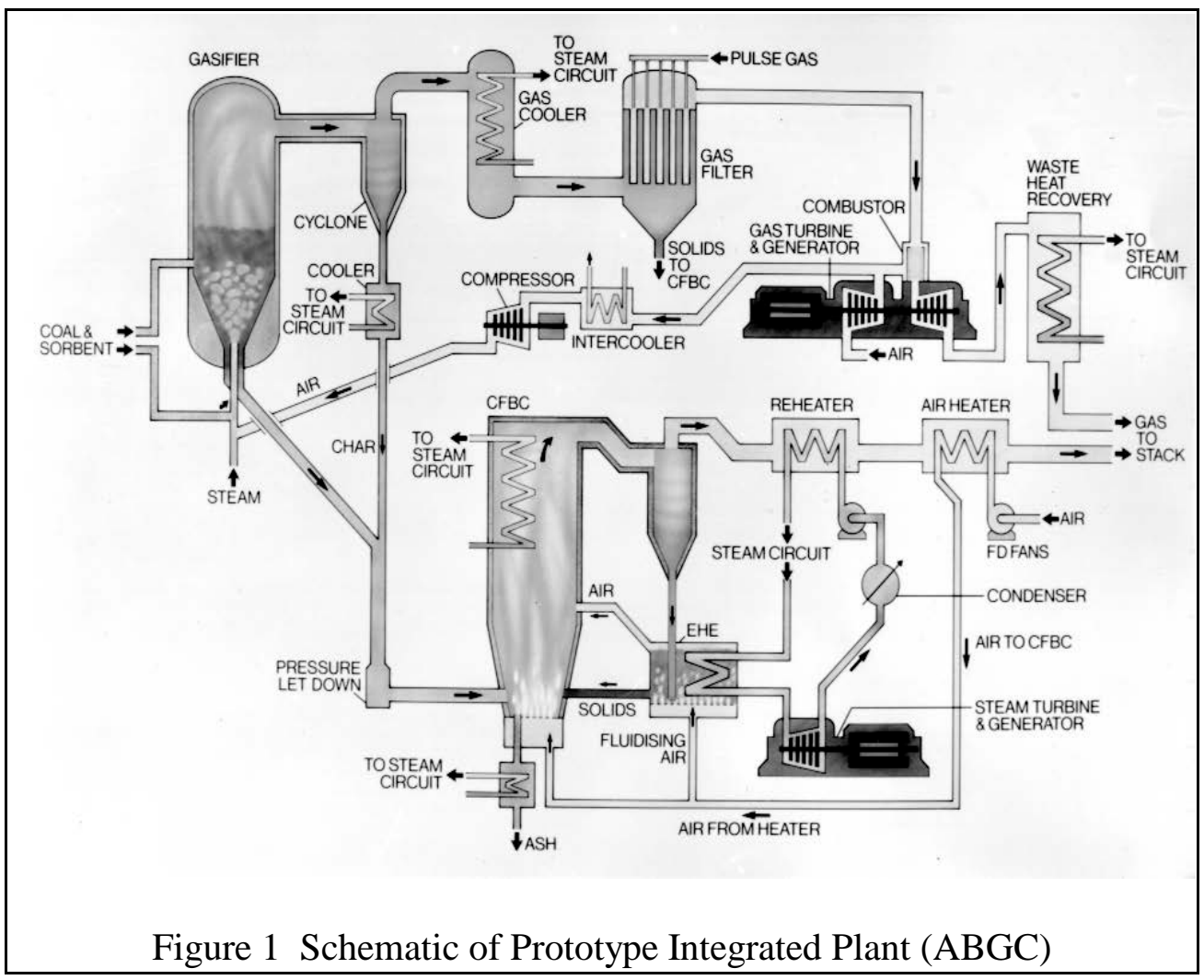

\subsection{Air Blown Gasification Cycle Description}

The basic functionality of the ABGC plant (as shown in Figure 1) can be summarised as follows: Coal, steam and air react in the gasifier to produce low calorific value fuel gas for combustion in a gas turbine. Limestone is added to remove sulphur and the temperature conditions in the gasifier result in low thermal NOx production. Approximately $10 \%$ of the carbon in the coal does not react in the gasifier. This is extracted via the ash removal system and fed to an atmospheric pressure circulating fluidised bed combustor (CFBC) operating at 
around $1150 \mathrm{~K}$. Here, the remaining carbon is completely combusted. A water/steam circuit removes heat from the CFBC water walls, exhaust gas heat exchangers and the gas turbine heat recovery steam generator. The resulting high pressure steam is fed to a steam turbine. Further details concerning the cycle are described by Donne et al, [1]

\subsection{Modelling The Air Blown Gasification Cycle}

One aspect of the Technology Centre’s responsibility in the CCPGG programme was the development of a dynamic simulation model and a control philosophy for the PIP, more details of which may be found in [1, 2]. In fulfilling this, the design and dynamic modelling requirements of specific components of the system, such as the gasifier, boost compressor, steam turbine and gas turbine were analysed. Furthermore, physical models of all the gas and steam cycle components used in the plant were developed, tested and validated as appropriate. These models were then integrated, together with the relevant control systems, to form the overall model of the PIP.

One of the reasons for modelling the PIP was to aid the development of a suitable control philosophy. Here, emphasis was placed on those aspects of the PIP that are not normally encountered in conventional power plants. The key components from this point of view are the gasifier, the gas turbine (running on low and variable calorific fuel-gas), the Circulating Fluidised Bed Combustor (CFBC) and the global plant control itself. There were two objectives for the control system analysis: primarily, to verify that the plant can be safely and adequately controlled; and secondly, to examine some of the more complex components of the PIP with a view to proposing safer, more economical, higher performance controllers using advanced control techniques.

The control scheme developed was shown to be capable of controlling the complete plant even in the event of a full-load rejection, which represents the most severe "trip" (or 
fault) condition likely to be encountered. Also adequate control of load acceptance and load reduction was demonstrated with the demanded power being followed accurately in both cases.

\subsection{The Gasifier}

The gasification plant for the PIP is based on the British Coal experimental gasifier, making use of the spouted fluidised bed gasification concept and can be considered as a reactor where coal is gasified with air and steam. In simple terms the gasification process works as described below.

Pulverised coal mixed with limestone, which captures sulphur originating in the coal, is conveyed by pressurised air into the gasifier. The air and injected steam not only fluidise the solids in the gasifier, but also react with the carbon and volatiles from the coal, producing a low calorific value fuel gas (approximately $4.5 \mathrm{MJ} / \mathrm{kg}$ or $12 \%$ that of Natural Gas). The remaining char (ash from coal, limestone and unreacted carbon) is removed as bed material from the base of the gasifier or carried out of the top of the gasifier as elutriated fines with the product gas. Under certain circumstances as much as $70 \%$ of the total char off-take leaves the gasifier as elutriated fines.

\subsection{The Non-Linear Gasifier Model}

The gasifier model has been developed using the Advanced Continuous Simulation Language (ACSL), [5], and is compatible with Framatome's Modular Modelling System (MMS), [6]. Figure 2 shows a schematic flow diagram representing the gasifier model chemistry. The different processes in the model include:

a) Drying process; the moisture in the coal and limestone is removed and added to the steam flow, dry limestone and ash are separated from the coal and fed to the 
desulphurisation process. The resulting dry ash free coal is an input to the pyrolysis process.

b) Desulphurisation process; the sulphur in the ash is captured by the dry limestone resulting in a flow of inerts which is added to the bed mass.

c) Pyrolysis process; dry ash free coal is devolatilised; the gases evolved and the resulting fixed carbon are available to the gasification process.

d) Gasification process; the chemical reactions modelled here are two exothermic combustion reactions and two endothermic gasification reactions, each with its own reaction rate. The unreacted carbon is added to the bed mass.

e) Mass Balance; a separate mass balance on the inerts and carbon is used to obtain the solids composition and hence the total mass of solids. The mass flow rate of elutriated char is calculated and added to the fuel gas.

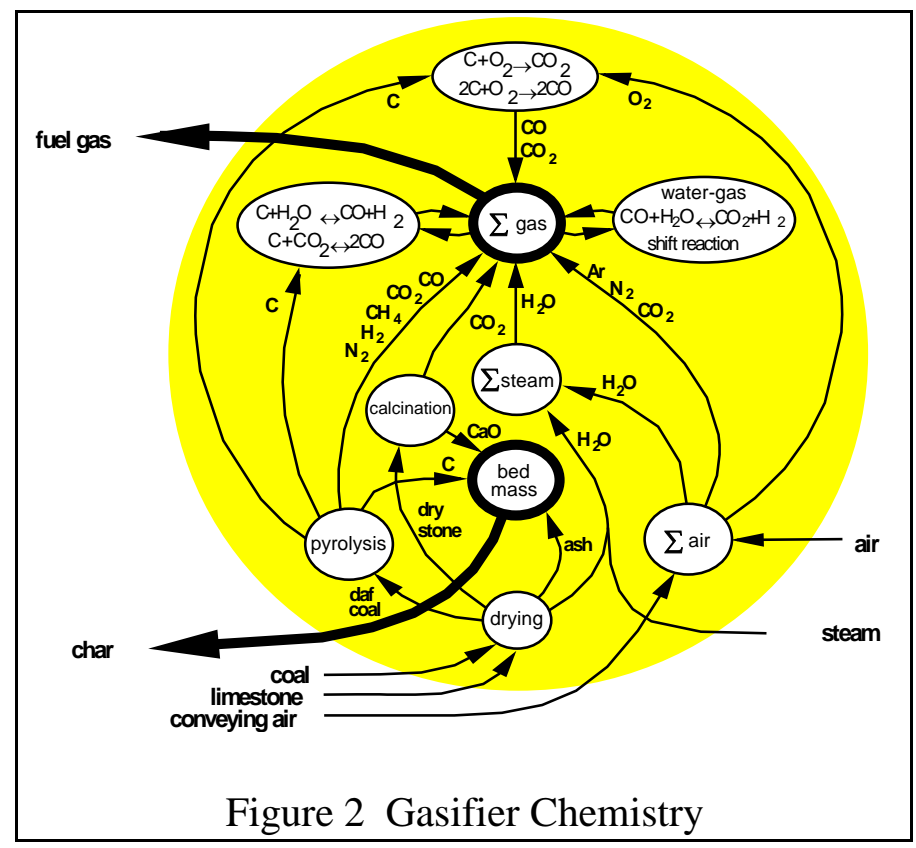

At the global level, there is an overall heat balance for gases and solids to obtain the specific enthalpy of the gas and the total enthalpy of the solids. This model has been validated using 
measured time histories from the British Coal experimental test facility and it was shown that the model predicts the main trends in fuel gas quality, i.e. calorific value or CV in Figure 3.

\section{THE BENCHMARK CHALLENGE SPECIFICATION}

This section describes the gasifier system, the linear models, the control system requirements and the performance tests for the challenge.

\subsection{System Description}

A functional layout of the gasifier is shown in Figure 3, below. It is a non-linear, multivariable component, having five inputs (coal, limestone, air, steam and char extraction) and four outputs (pressure, temperature, bed mass and gas quality) with a high degree of cross coupling between them. In addition, there is a disturbance input (PSINK) representing pressure disturbances induced as the gas turbine fuel inlet valve is opened and closed.

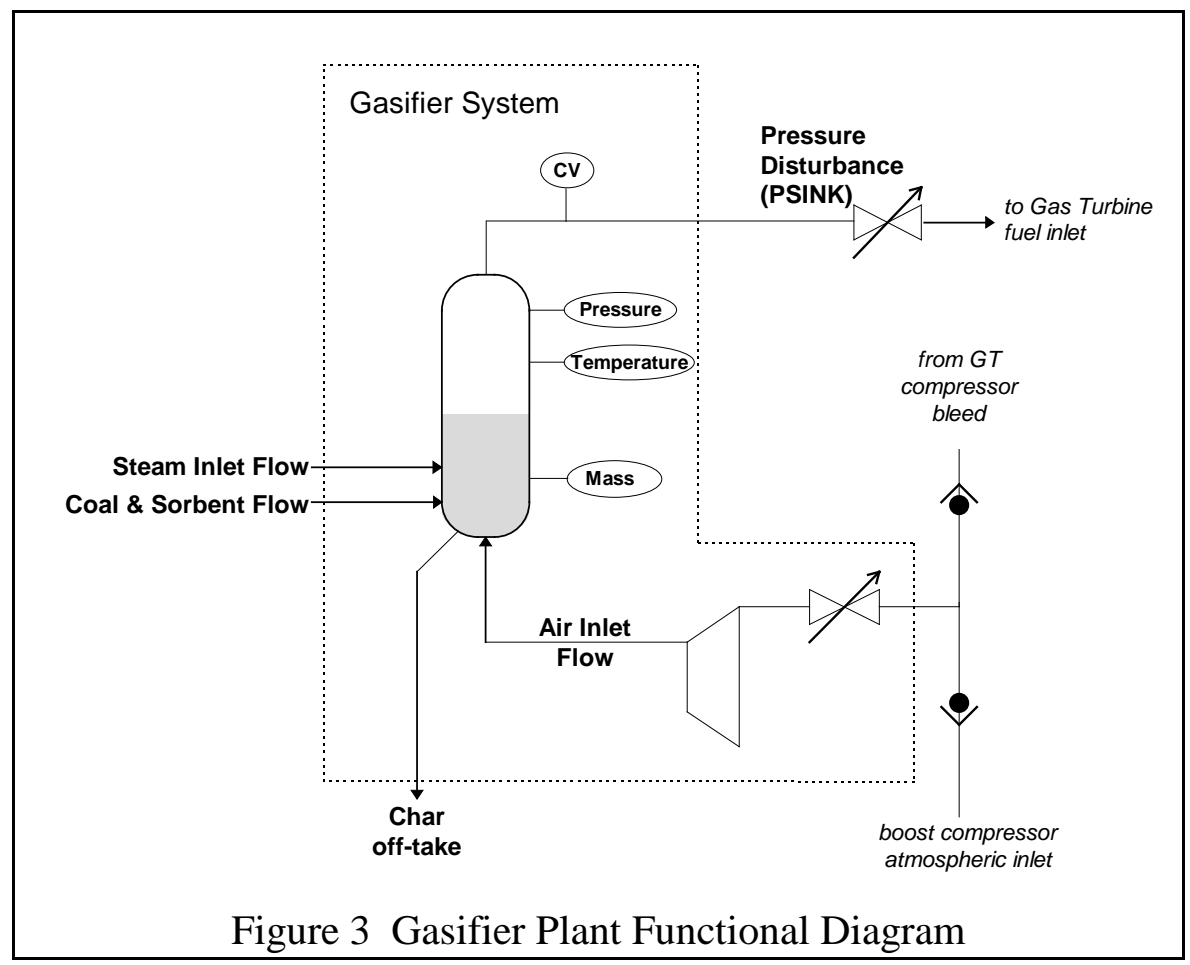


The controllable inputs are:
1. Char extraction flow - WCHR $\left(\mathrm{kg} \mathrm{s}^{-1}\right)$
2. Air mass flow $\quad-\quad$ WAIR $\left(\mathrm{kg} \mathrm{s}^{-1}\right)$
3. Coal flow $\quad-\quad$ WCOL $\left(\mathrm{kg} \mathrm{s}^{-1}\right)$
4. Steam mass flow $\quad-\quad$ WSTM $\left(\mathrm{kg} \mathrm{s}^{-1}\right)$
5. Limestone mass flow - $\quad W L S\left(\mathrm{~kg} \mathrm{~s}^{-1}\right)$

The disturbance input is:
6. Sink pressure
- $\quad$ PSINK $\left(\mathrm{N} \mathrm{m}^{-2}\right)$

The outputs are:
1. fuel gas calorific value - CVGAS $\left(\mathrm{J} \mathrm{kg}^{-1}\right)$
2. bed mass
- $\quad$ MASS (kg)
3. fuel gas pressure $\quad-\quad P G A S\left(\mathrm{~N} \mathrm{~m}^{-2}\right)$
4. fuel gas temperature - TGAS (K)

Note that: Limestone absorbs sulphur in the coal. Thus WLS should be set to a fixed ratio of WCOL - nominally 1:10 limestone to coal. This leaves effectively 4 degrees of freedom for the control design.

\subsection{The Gasifier Linear Models}

Three continuous time, state space, linear models were obtained from the non-linear ACSL model at operating points of $100 \%, 50 \%$ and $0 \%$ load. These models were validated against the non-linear model for a series of (10\% of nominal) step inputs; as an example, the validation results for the $100 \%$ load model responding to a $10 \%$ step increase in steam flow are shown in Figure 4. 

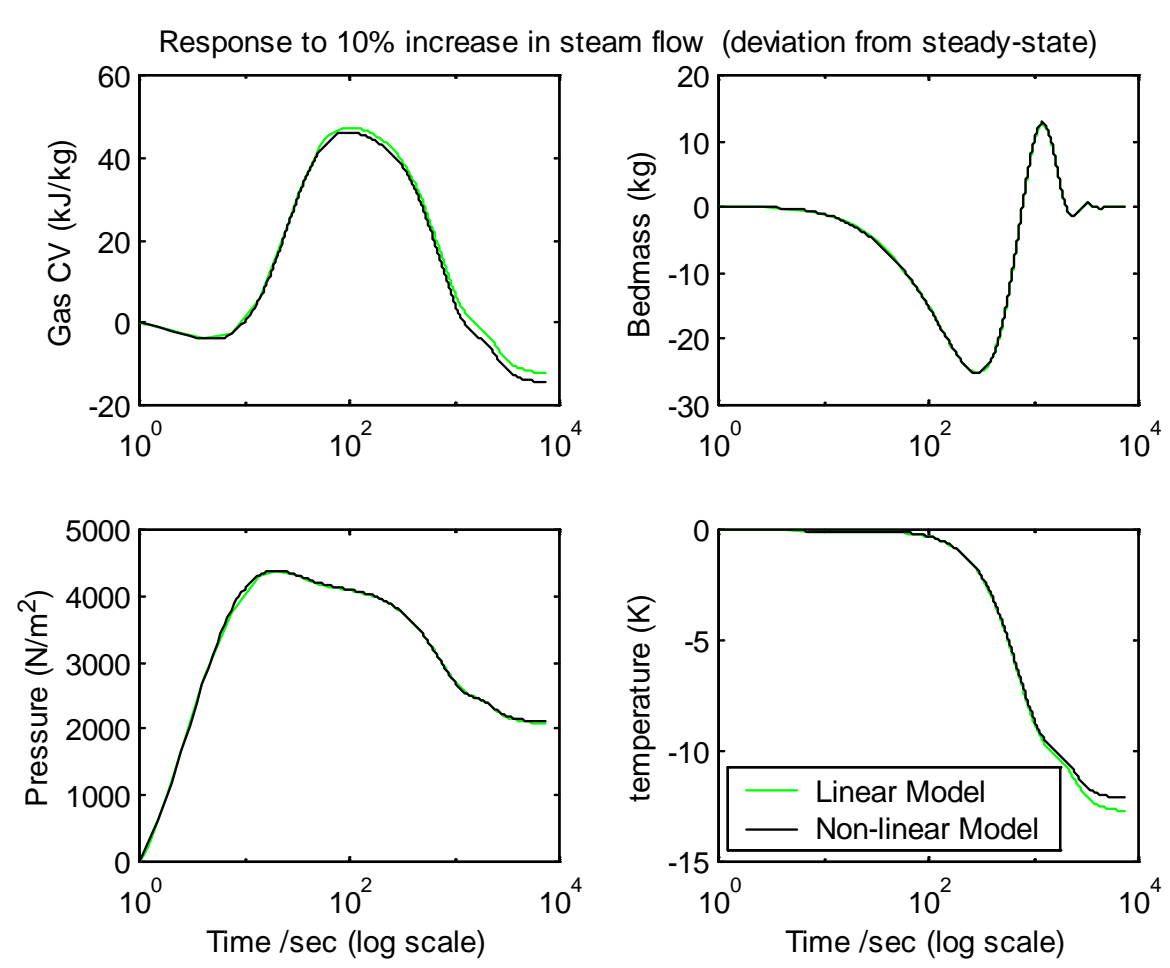

Figure 4 Validation results 100\% Load - Step in Steam Flow

For the validation, a PI controller manipulates the char off-take in order to maintain the bed mass - this is required because the bed mass level is marginally stable and over the run time (7200sec or 2hrs) the non-linear plant would have deviated significantly from the operating point of the linearisation. The marginal stability of the bed mass has implications on any system identification experiments which might be performed on the plant - a stabilising controller would be required keep the bed mass at its set point so that the other variables behave as desired in the short-term. It is worth noting that the linear benchmark challenge models are also marginally stable and that further investigation has shown them to be valid over an operating region that exceeds the region bounded by the challenge control specifications. 


\subsection{Control System Specification}

The controller should regulate the outputs, within the constraints described below.

Input Limits: the input flow limits and the input rate of change limits, shown in Table 1 below, cannot be exceeded (since they are associated with physical properties of the actuator devices).

\begin{tabular}{|l|c|c|c|c|}
\hline \multicolumn{1}{|c|}{ Input } & name & Max $\left(\mathrm{kg} \mathrm{s}^{-1}\right)$ & $\min \left(\mathrm{kg} \mathrm{s}^{-1}\right)$ & Rate $\left(\mathrm{kgs}^{-2}\right)$ \\
\hline Coal Inlet Flow & WCOL & 10 & 0 & 0.2 \\
Air Inlet flow & WAIR & 20 & 0 & 1.0 \\
Steam Inlet Flow & WSTM & 6.0 & 0 & 1.0 \\
Char Extraction & WCHR & 3.5 & 0 & 0.2 \\
\hline
\end{tabular}

Table 1 Control Input Limits

\section{Control Objectives (output limits):}

- $\quad$ the CV fluctuation should be minimised and should always within $\pm 10 \mathrm{KJ} \mathrm{kg}^{-1}$.

- $\quad$ the pressure fluctuation should be minimised and should always be within \pm 0.1 bar .

- $\quad$ bed mass should remain within $\pm 500 \mathrm{~kg}$ from the set-point.

- $\quad$ temperature fluctuation should be kept to a minimum, always within $\pm 1^{\circ} \mathrm{C}$.

Finally, note that the stated input and output limits are only estimates of those that might prevail on the actual system (since the gasifier has yet to be designed and built).

\subsection{Performance Tests:}

The two test cases described below consist of a pressure step disturbance of -0.2 bar to the system - corresponding to a step in the gas turbine inlet valve position in reaction to a load change and a sine wave pressure disturbance of amplitude 0.2 bar and frequency of $0.04 \mathrm{~Hz}$ corresponding to low frequency movements of the inlet valve in reaction to changes in grid frequency, [7]. 
In order that a range of control system design techniques might be compared on a basis which is as fair as possible, the following design criteria and test cases should be adhered to:

1) The control design is to be undertaken for the $100 \%$ load operating point.

2) Apply a pressure step disturbance (PSINK) of -0.2 bar to the system, at $t=30$ seconds. - run the simulation for 5 minutes, until $t=300$ seconds and calculate the integral of absolute error for the CV and Pressure outputs over the complete run. - note any constraint violations (recall that input constraints are hard and fixed).

3) Apply a sine wave pressure disturbance of amplitude 0.2 bar and frequency of $0.04 \mathrm{~Hz}$. - over a 300 second run calculate the integral of absolute error (IAE) as before. - note any constraint violations (recall that input constraints are hard and fixed).

4) Repeat steps 2 and 3 at the $50 \%$ and $0 \%$ load operating points, again calculating the integral of absolute error performance criterion.

\section{CONCLUSIONS}

This paper has given details of the Benchmark Challenge on Gasifier Control. In addition to providing background information on the gasifier plant, the paper has presented the control system specification and test cases for the challenge. It is considered that the control problems, as posed, are reasonably representative of those that would occur in practice. However, it is envisaged that this initial control study will highlight potential problem areas, some of which would be addressed during detailed design and sizing of the gasifier plant.

\section{ACKNOWLEDGEMENTS}

The authors would like to acknowledge the financial assistance of the European Community THERMIE programme, under grant number SF/00257/97/FR/GB. In addition, the authors are 
grateful to the management of ALSTOM Power Technology Centre for permission to publish this article.

\section{REFERENCES}

[1] Donne M.S, R. Dixon, A.W. Pike, A.J.L. Odeku, and B.E. Ricketts, Dynamic modelling of the ABGC prototype integrated plant, DTI Coal Research and Development Programme, ETSU Report No. COAL R143, 1998.

[2] Pike A.W., M. S. Donne and R. Dixon, Dynamic Modelling and Simulation of the Air Blown Gasification Cycle Prototype Integrated Plant, Int. Conf. on Simulation '98, York University, IEE publication no. 457, 1998, pp 354-361.

[3] HMSO, The Prospects for Coal: Conclusions of the Governments Coal Review, CM2235, HMSO, March 1993.

[4] ETSU, Gasification of Solid and Liquid Fuels for Power Generation, Technology Status Report, TSR008, Manager - Cleaner Coal Technology Programme, ETSU, Harwell, Didcot, Oxfordshire, OX11 0RA, December 1998.

[5] Mitchell and Gauthier Associates Inc., Advanced Continuous Simulation Language, Mitchell and Gauthier Associates Inc., 200 Baker Avenue, Concord, Massachusettes, 01742, USA.

[6] Framatome Technologies Inc., Modular Modelling System Theory Manual, Framatome Technologies Inc., 3315 Old Forest Road, P.O. Box 10935, Lynchburg, VA 24506-0935, USA.

[7] de Mello, F.P., R.J. Mills and W.F. B'Rells, Automatic Generation Control, Part I: process modelling, Part II: digital control techniques, IEE Trans. on Power Apparatus and Systems, Vol. PAS-92, No.2, 1973, pp.710-725. 